5.

Derecho constitucional 

Revista de Derecho

de la Pontificia Universidad Católica de Valparaíso XXXIII (Valparaíso, Chile, $2^{\text {do }}$ Semestre de 2009)

[pp. 371 - 390]

\section{LA DISTRIBUCIÓN DE POTESTADES NORMATIVAS EN LA CONSTITUCIÓN: POTESTADES REGLAMENTARIAS ADMINISTRATIVAS, AUTOS ACORDADOS Y FACULTADES DEL FISCAL NACIONAL}

["Distribution of Regulatory Authorities in the Constitution Administrative Regulatory Authorities, Agreed Proceedings and Faculties of the National Prosecutor"]

\section{Eduardo Aldunate Lizana* \\ Pontificia Universidad Católica de Valparaíso, Chile}

\begin{abstract}
RESUMEN
El principal problema de la distribución constitucional de poderes entre Ejecutivo y Legislativo ha sido, desde 1981, la definición del límite entre la ley y el reglamento. El presente trabajo reclama la necesidad de identificar y analizar otro grupo de problemas que surgen de la configuración de potestades regulatorias fuera del ámbito de la ley. Estos problemas se originan en la habilitación constitucional a órganos no dependientes del Presidente, para dictar una regulación, a pesar de la habilitación residual general contenida en el artículo 32 No 6 de la Constitución.

Palabras Clave: Potestad reglamentaria del Presidente de la República - Potestad reglamentaria de entes administrativos - Autos acordados de la Corte Suprema.
\end{abstract}

\begin{abstract}
The main problem in the constitutional distribution of powers between the Executive and Legislative has been, since 1981, the border between legislation and governmental regulation (regulatory decrees). The present work claims for the analysis the need to identify another set of problems, that arise from the constitutional configuration of the regulatory powers that are outside the scope of legislation. These problems have their origins in the the legal habilitation to non presidential organs to undertake a regulation, in spite of the general and residual regulatory power of the President as granted in sec. 32 No 6 of the Constitution.

KEYWORDS: Regulatory powers of the President - Regulatory powers of administrative agencies - Regulatory acts of the Supreme Court.
\end{abstract}

* Profesor titular de Derecho Constitucional en la Escuela de Derecho de la Pontificia Universidad Católica de Valparaíso. Dirección postal: Escuela de Derecho, Pontificia Universidad Católica de Valparaíso, Av. Brasil 2950, Valparaíso, Chile. Correo electrónico ealdunat@ucv.cl. El artículo pertenece al Proyecto FONDECYT No 108618, cuyo investigador responsable es Eduardo Cordero. 


\section{INTRODUCCIÓN}

La tesis que se plantea en este trabajo es que nuestra Constitución contiene un sistema de distribución de competencias normativas, no sólo en la contraposición entre dominio legal y potestad reglamentaria del Presidente de la República ${ }^{1}$, sino también al interior del ámbito que no corresponde a la ley, y que se encuentra otorgado a lo que podría denominarse, en oposición a la potestad legislativa, potestad reglamentaria en sentido amplio. Desde la entrada en vigencia de la Constitución, y particularmente durante la década de 1990, la discusión doctrinaria y las principales cuestiones sometidas al conocimiento de tribunales han recaído sobre la delimitación de la potestad reglamentaria frente a la potestad legislativa ${ }^{2}$, dejando de lado la cuestión relativa a la configuración constitucional de la potestad reglamentaria. Sin embargo, ésta no es, como podría pensarse en un primer momento, una cuestión sencilla. Las dificultades surgen de dos circunstancias:

i) la Constitución asigna, frente al dominio legal, un dominio reglamentario residual en beneficio del Presidente de la República, junto a habilitaciones regulatorias específicas en favor de otros órganos constitucionales;

ii) las habilitaciones regulatorias distintas a la potestad reglamentaria del Presidente de la República carecen, en la Constitución, de un criterio delimitador respecto de aquella.

Respecto del primer punto, se examinará aquí la situación de potestades reglamentarias otorgadas por ley a órganos administrativos; respecto del segundo, se discutirá la delimitación de la potestad de los tribunales para dictar autos acordados, y parcialmente respecto de ambos, se examinará la situación de las potestades normativas del fiscal nacional.

${ }^{1}$ Sea cual sea el límite que divide los respectivos elementos de esta contraposición. No está dentro del objeto del trabajo el precisar dicho límite, y por lo tanto baste expresar aquí la adhesión a la tesis de Teodoro Ribera en cuanto a que nuestro sistema no puede denominarse, en rigor, un sistema de dominio máximo legal, ya que lo que determina la competencia legislativa no es solamente un criterio de materias, sino también de intensidad regulatoria (artículo 63 No 20) y de una técnica legislativa específica (la codificación, artículo 63 № 3 ).

${ }^{2}$ Aunque no sea demasiado llamativo, es interesante destacar que en todo este tiempo no se ha dado ningún caso en que el Presidente de la República haya disputado a la producción legislativa algún ámbito como reservado a su potestad reglamentaria, a pesar de que en muchos casos ello era perfectamente plausible: especialmente tratándose de regulaciones legislativas detalladas en materias en que la Constitución sólo entrega a la ley la regulación de aspectos básicos. Como ejemplo baste mencionar la regulación de la previsión social. 
El análisis se realiza desde la perspectiva jurídico-positiva y por lo tanto las conclusiones sobre la inconstitucionalidad de ciertas disposiciones legales o la falta de fundamento de determinadas competencias reglamentarias no implican una toma de posición respecto de la conveniencia de un determinado modelo de distribución de las mismas.

\section{POTESTAD REGLAMENTARIA PRESIDENCIAL RESIDUAL Y PRÁCTICAS LEGISLATIVAS INCONSTITUCIONALES}

Nuestra Constitución contiene en los artículos 32 № 6 y 63 una distribución de competencias que, en materia de creación de textos normativos, aparece cerrada. A la ley corresponde regular las materias señaladas en el artículo $63 \mathrm{~N}^{\text {os }} 1$ a $19^{3}$, y, en términos de intensidad regulatoria, toda otra materia con tal de que acometa dicha regulación estableciendo las bases esenciales de un ordenamiento jurídico (artículo 63 No 20). El remanente es entregado al Presidente de la República en el artículo 32 No 6, en la calidad de jefe de gobierno y de la administración del Estado que le atribuye el artículo $24^{4}$. Las fuentes constitucionales de esta distribución competencial deben ser completadas con preceptos que, en detrimento de las facultades reglamentarias del Presidente de la República, contemplan, ya sea de manera expresa una facultad de dictar reglamentos (facultad de las cámaras para dictar sus reglamentos [artículo 56], misma facultad del Consejo de Seguridad Nacional [artículo 107]), ya sea una habilitación para participar en la creación de textos normativos, como en el caso del Banco Central (inciso final del artículo 109 "acuerdos que signifiquen [...] establecer normas") de los consejos regionales ("órgano de carácter normativo" [artículo 113]), y los concejos comunales ("funciones normativas" [artículo 119]), y, tras la reforma del año 2005, la facultad de dictar autos acordados de las cortes de apelaciones, la Corte Suprema y el Tribunal

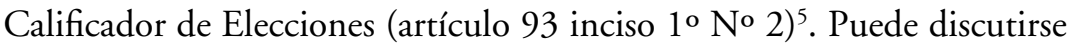

${ }^{3}$ En adelante, toda referencia a artículos que no indique fuente específica debe entenderse referida al texto constitucional vigente.

${ }^{4}$ Esta referencia al artículo 24 no es meramente teórica. Al menos Silva Cimma, Enrique, Derecho administrativo chileno y comparado. Introducción y fuentes (4a edición, Santiago de Chile, Editorial Jurídica de Chile, 1996), p. 157, parece ver en ella un elemento definitorio del contenido de la potestad reglamentaria presidencial.

${ }^{5}$ Lo relevante no es la mera consagración constitucional del órgano, sino que la habilitación constitucional de una potestad regulatoria. Así por ejemplo, la referencia al Consejo Nacional de Televisión no contiene una habilitación para dictar normas: de este modo, y aunque se encomiende a una ley de quórum calificado señalar las funciones y atribuciones del Consejo, esta referencia no puede tener el efecto de reducir competencias normativas del Presidente de la República, por ejemplo, al 
el contenido específico respecto del cual, en cada uno de estos casos, se produce una atribución de competencias normativas en menoscabo del ámbito de la potestad reglamentaria presidencial; pero en todos estos casos ella tiene sustento constitucional. Queda entonces planteada la tarea para el trabajo dogmático, de construir los criterios que permitan circunscribir el ámbito de competencia regulatoria que la correspondiente ley puede otorgar a partir de dicha habilitación ${ }^{6}$.

En este punto es interesante destacar un particular fenómeno de nuestra praxis institucional. Asumida la naturaleza reglamentaria de las atribuciones normativas que tiene el Banco Central, no se ha planteado a su respecto el cuestionamiento que si se ha hecho del ejercicio de la potestad reglamentaria del Presidente de la República, en cuanto a la extensión de la misma frente al ámbito de la ley. Se encuentra, en efecto, una serie de disposiciones normativas que emanan del Banco Central y que, de haber sido dictadas en ejercicio de las atribuciones presidenciales, de seguro hubiesen sido requeridas ante el Tribunal Constitucional, y eventualmente declaradas inconstitucionales, por haber regulado, vía reglamento, el ejercicio de la libertad económica prevista en el artículo 19 № 21.

La conclusión que se obtiene de la apreciación sistemática de estas disposiciones es que ellas fijan, a nivel constitucional, una distribución de competencias regulatorias que no puede ser alterada por la ley, de tal modo que, y salvo en el caso de los preceptos que modulan la competencia residual de la potestad reglamentaria del presidente de la república ${ }^{7}$, la ley no puede otorgar competencias regulatorias a órganos que quedan fuera del

entregarle la facultad de autorregularse [artículo 12 letra j), de la ley No 18.838] o de regular la transmisión y recepción de la televisión por satélite [artículo 12 letra f) de dicha ley].

${ }^{6}$ Desde ya cabría comenzar distinguiendo entre aquellas habilitaciones constitucionales abiertas -como facultades normativas- y aquellas qué sólo habilitan al órgano para una autorregulación, o sea, para el ejercicio de una potestad reglamentaria interna, cual es el caso de las cámaras, en sus respectivos reglamentos, y del Consejo de Seguridad Nacional.

${ }^{7}$ A fin de no distraer la atención del objeto de este trabajo no se ha entrado al análisis del contenido de la potestad reglamentaria en un sentido amplio: se considera, aquí, que ella no sólo involucra la producción de textos con función normativa, sino también las demás facultades asociadas a la aplicación de la ley por un órgano ejecutivo: interpretación de los preceptos pertinentes en el cumplimiento de sus funciones, incluida la fiscalización; ejercicio de pretensiones sancionadoras ante órganos jurisdiccionales o como aplicación directa de sanciones administrativas; poder de instrucción (para dar órdenes concretas en oposición a la producción de textos normativos usualmente llamados "normas generales"). Sin perjuicio de lo anterior, se centra el análisis y la crítica en la producción de textos normativos, cualquiera sea la denominación que éstos reciban. 
campo de acción jurídica del presidente, al menos en términos de jerarquía, entendida ésta como potestad de instrucción. De este modo, las leyes que otorgan facultades regulatorias a entes que no cuentan con habilitación constitucional de potestad normativa, y que presentan autonomía jurídica respecto del Presidente de la República, alteran facultades constitucionalmente entregadas al mismo y son, en consecuencia, inconstitucionales.

Lo que interesa aquí es el caso de numerosas leyes en que se ha otorgado a órganos administrativos facultades normativas, sin sustento constitucional expreso. Es posible distinguir aquí diversas hipótesis.

i) En aquellos casos en que el respectivo órgano se encuentra bajo la potestad de instrucción del Presidente de la República, esta radicación de facultades normativas no plantea problemas, en cuanto sigue la regla del artículo 32 No 6 y el Presidente de la República podrá, a través de las respectivas instrucciones, imperar sobre el ejercicio de esta potestad reglamentaria.

ii) Hay casos en que, dentro de la estructura jerárquica de gobierno y administración, se crean instancias o procedimientos que sustraen del ámbito de acción del Presidente de la República algunos aspectos del ejercicio de la potestad reglamentaria, de tal modo que el poder de decisión queda radicado en un órgano exento de su potestad de instrucción. Esto sucede, por ejemplo, en el caso de la legislación pesquera, donde, si bien es cierto la forma de algunas decisiones sigue siendo la de decreto supremo, o resolución, su contenido es aportado por una decisión del Consejo Nacional de Pesca, misma que no puede ser determinada ni enervada por la autoridad ejecutiva ${ }^{8}$. Esta sustracción o condicionamiento del ejercicio de la potestad reglamentaria presidencial en favor de la potestad decisoria de un órgano que no depende del jerarca ejecutivo aparece como inconstitucional.

iii) En un tercer grupo encontramos órganos que sólo aparecen secundariamente vinculados al Presidente de la República, no por la potestad de instrucción, sino por la posibilidad de remover al titular del respectivo órgano (cosa que sucede con los superintendentes en cuanto funcionarios

${ }^{8}$ Es así como, por ejemplo, si el montante de la cuota global anual de captura de algún recurso hidro-biológico determinado por el Consejo Nacional de Pesca no es del agrado del gobierno, éste no tiene facultades para modificarlo y ni siquiera para negarse a dictar el respectivo decreto de cuota. Cfr. artículos 145 y 26 de la Ley No 18.892: General de pesca y acuicultura, y las disposiciones de la Ley No 19.713 que establece el límite máximo de captura por armador. Del mismo modo, y con naturaleza más claramente reglamentaria, aun cuando haya sido de su iniciativa, no parece ser jurídicamente viable que el gobierno se niegue a la producción del decreto que formaliza la declaración de estado de plena explotación de un recurso -lo que implica un cambio del régimen legal aplicable- una vez que el Consejo ha otorgado su aprobación a la misma. 
de la exclusiva confianza del Presidente de la República ). En estos casos, el Presidente de la República sólo puede confiar en la presión y expectativa de cumplimiento de sus directrices que ejerce a través de la posibilidad de remoción, pero no tiene potestad jurídica de instrucción sobre el respectivo órgano. Resulta de ello una atribución a nivel legal, de potestades reglamentarias fuera de la órbita de atribuciones jurídicas del Presidente de la República, en contra de la expresa distribución resultante de los preceptos constitucionales ya mencionados. Un claro ejemplo dentro de este grupo lo encontramos en el caso del Servicio Nacional de Aduanas. Se trata de un órgano dotado de personalidad jurídica y, según expreso texto de la ley, de autonomía administrativa'; no obstante ello, el director del servicio es nombrado por el Presidente de la República, siendo de su exclusiva confianza y por tanto, de su libre remoción ${ }^{10}$. Dentro de sus facultades se contemplan varias de naturaleza normativa y que pueden considerarse de carácter reglamentario: fijar y modificar la organización interna de las unidades del servicio, interpretar administrativamente disposiciones legales y reglamentarias, dictar normas de régimen interno, dictar normas para el cumplimiento de la legislación y reglamentación aduanera, dictar resoluciones generales en materia de personal ${ }^{11}$. Cosa similar ocurre con las superintendencias ${ }^{12}$. En el caso de la Superintendencia de Bancos e Instituciones Financieras, la atribución de potestades reglamentarias no sólo se encuentra contemplada para regular la actividad económica -ámbito en el cual esta facultad ha sido arduamente disputada al Poder Ejecutivo- sino que también está dotada de una potestad sancionadora ${ }^{13}$; más aún, se otorgan al superintendente respectivo facultades para aplicar medidas concretas restrictivas de la actividad del giro de los bancos y entidades financieras ${ }^{14}$.

${ }^{9}$ Artículo 1 del Decreto con fuerza de ley No 1, de 1997, de Hacienda: Ordenanza de Aduanas.

${ }^{10}$ Artículo 4 del Decreto con fuerza de ley No 329, de 1979: Ley orgánica del Servicio Nacional de Aduanas.

${ }^{11}$ Artículo 4 del Decreto con fuerza de ley No 329, de 1979, en diversos numerales.

${ }^{12}$ Cfr. el Decreto-ley No 3538: ley orgánica de la Superintendencia de Valores y Seguros, artículo 4 letras a), e), i) ñ), u); la Ley No 18.933: de Instituciones de salud previsional, artículo $3 \mathrm{~N}^{\text {os }} 2,7,8,9,9$ bis, 10 y 13.

${ }^{13}$ La ley habla de "órdenes legalmente impartidas" cuyo incumplimiento puede ser sancionado con multas de hasta cinco mil unidades de fomento (artículo 19 del Decreto-ley No 1.097: Ley General de Bancos). El superintendente tiene facultades interpretativas, para dictar instrucciones (artículo 12) y normas de carácter general (artículo 15).

${ }^{14}$ Artículo 20 del Decreto-ley No 1.097: Ley General de Bancos. 
d) El último grupo es el más cuestionable, desde un punto de vista constitucional: se trata de casos en que se otorgan potestades reglamentarias a órganos propiamente autónomos. Así por ejemplo la Ley orgánica constitucional sobre inscripciones electorales y Servicio Electoral otorga al director de éste, en su calidad de jefe del servicio electoral, la facultad de "dictar resoluciones generales [...] necesarias para el ejercicio de sus atribuciones" [artículo 93, letra i)] así como la de "dar instrucciones generales sobre la aplicación de las normas electorales" para su ejecución por los organismos establecidos en ellas" [artículo 93 letra k)].

Para cerrar este acápite, es preciso hacer mención a un fenómeno que, si bien en su naturaleza es distinto a la atribución legislativa de potestades reglamentarias, en sus efectos resulta muy similar. La Contraloría General de la República se ha auto-atribuido, a partir de la forma como interpreta sus facultades para emitir dictámenes, y el modo en que entiende el carácter vinculante de los mismos para los fiscales y abogados que no ejercen defensas judiciales, una verdadera facultad invalidatoria de actos antijurídicos, asociada a un poder de instruir al respectivo órgano para que dicte el acto de reemplazo, o que la CGR estima pertinente ${ }^{15}$. Esta práctica de auto-atribución de una potestad de instrucción atenta contra la específica disposición del artículo 32 No 6 , en cuanto radica en un órgano administrativo distinto al Presidente de la República la potestad para ordenar la producción de ciertos actos jurídicos públicos en el ámbito de la administración ${ }^{16}$.

\section{DOMINIO LEGAL MÁXIMO Y FACULTADES LEGISLATIVAS SOBRE LA POTESTAD REGLAMENTARIA}

La explicación de esta proliferación de disposiciones legislativas sin

\footnotetext{
${ }^{15}$ Cfr. Aldunate Lizana, Eduardo, La evolución de la función de control de la Contraloría General de la República, en Revista de Derecho de la Pontificia Universidad Católica de Valparaíso 26 (2005, 20 Semestre), pp. 19-29. Esta práctica de la Contraloría muestra la necesidad de contar con claridad conceptual, en materia jurídica, para el desarrollo institucional y político del país. Sólo una deficiente comprensión del sentido de la potestad reglamentaria del Presidente de la República, de su calidad de jerarca de la administración y del valor y función de los dictámenes explica la evolución de que da cuenta el trabajo citado en esta nota.

${ }^{16} \mathrm{Si}$ se revisa la Ley orgánica constitucional de la Contraloría General de la República a la luz del artículo 7 inciso $2^{\circ}$ de la Constitución, no es posible encontrar en ninguna parte la consagración expresa de esta facultad. $\mathrm{Y}$ es difícil tratar de interpretar las disposiciones constitucionales que regulan la Contraloría, en el sentido de afirmar que dicha atribución (invalidatoria de un acto, y de instrucción para dictar el acto de reemplazo) se encuentra contemplada de manera directa en la Constitución.
} 
amparo constitucional, y claramente contrarias a la distribución de competencias normativas que hace la Carta es sorprendente, por lo obvia. La modificación introducida por la Constitución de 1980 al sistema de dominio legal de la Carta de 1925 pareció muy evidente ${ }^{17}$ en lo relativo, justamente, a las atribuciones del legislativo contrapuestas a las facultades reglamentarias del Presidente de la República; pero no pasó lo mismo -y más bien fue omitida por completo- en sus efectos relativos a las atribuciones del legislativo para regular la potestad reglamentaria del Ejecutivo. En efecto, en un sistema de dominio mínimo legal, y teniendo por norma de clausura a la ley, ésta no sólo puede regular cualquier materia sino también estructurar de cualquier modo el ejercicio de las potestades reglamentarias al interior del Ejecutivo, desgajándolas, en su caso, de la atribución constitucional general de potestad reglamentaria al Presidente de la República. Es así como puede sustraer ámbitos completos de dicha potestad y otorgársela a órganos autónomos, o bien radicarla en órganos centralizados desvinculándolos de la potestad de instrucción del Presidente de la República. De allí el sentido de distinguir, en ese contexto, una potestad reglamentaria originaria, de fuente constitucional, y una potestad reglamentaria derivada, de fuente legal. En cambio, en un sistema como el adoptado por la Carta de 1980, la división constitucional de competencias entre potestad legislativa y potestad reglamentaria tiene como principal efecto eliminar la posibilidad de que, vía legislativa, se altere la plenitud de competencia reglamentaria otorgada al Presidente, salvo en aquellos casos en que la propia Constitución contiene una habilitación al legislador en este sentido.

El escaso material existente sobre la materia podría presentarse como prueba de la falta de percepción de que la cuestión aquí expuesta plantea un problema constitucional; o al menos, de una percepción disminuida frente al tema de la delimitación de la potestad reglamentaria frente a la potestad legislativa. Incluso en los casos en que determinados tópicos podrían haberse tratado desde la perspectiva de la configuración legislativa de la potestad reglamentaria, ellos han sido estudiados desde la perspectiva de la contraposición entre potestades legislativas y reglamentarias. Eduardo Cordero Quinzacara, en su extensa e interesante memoria de grado relativa a la potestad reglamentaria, describe el estado de la cuestión hacia mediados de la década de los 90. En su trabajo, la modificación legislativa de la distribución constitucional de potestades reglamentarias

${ }^{17}$ Habría que decir "aparentemente evidente": hasta la fecha, los reglamentos distinguibles como dictados en el ámbito de la potestad reglamentaria autónoma son casi irrelevantes a nivel institucional, en número y materias reguladas 
no aparece como un tema relevante; sí, en cambio, la discusión sobre la remisión normativa como un tópico desarrollado - por la jurisprudencia y la doctrina- en el espectro temático de la relación ley-reglamento ${ }^{18}$. Por su parte, en lo que se puede considerar una obra autorizada de referencia en materia de Derecho administrativo chileno, la de Enrique Silva Cimma, la cuestión de la atribución de competencias reglamentarias aparece descrita del siguiente modo: "En este sentido, pues, la potestad reglamentaria corresponde preferentemente al Presidente de la República. Sin embargo, esta facultad de dictar normas de carácter general, si bien en forma más restringida, la entrega la ley en determinados casos a otras autoridades, v.gr. los Municipios (sic) y los Entes Autónomos [sic]"19. En la doctrina constitucional, don Alejandro Silva Bascuñán no discute, en la parte pertinente de su Tratado de Derecho constitucional, los límites de la potestad reglamentaria del Presidente en términos de las atribuciones o habilitaciones reglamentarias otorgadas a otros órganos ${ }^{20}$.

\section{FACULTADES REGLAMENTARIAS DE LOS TRIBUNALES: LOS AUTOS ACORDADOS}

Junto con el problema reseñado, la potestad reglamentaria del Presidente de la República se ve enfrentada a otra potestad reguladora. Esta es la facultad de algunos tribunales para dictar autos acordados. Tal y como sucede con el tema planteado precedentemente, se trata de una materia poco tratada por la doctrina. La importancia relativa que los autos acordados han ganado el último tiempo en nuestro sistema de fuentes es apreciable. Conocida es la posición del auto acordado que regula el procedimiento en el caso de la acción de protección. Más recientemente, la propia ley que crea el Tribunal de Contratación Pública encarga a un auto acordado, pero de la Corte Suprema, la regulación de aspectos del funcionamiento de ese tribunal ${ }^{21}$. Incluso el ejercicio de derechos consti-

${ }^{18}$ Cordero Quizacara, Eduardo, La potestad reglamentaria en el Derecho público chileno (Memoria de prueba para optar al grado de licenciado en ciencias jurídicas y sociales, Facultad de Ciencias Jurídicas y Sociales de la Universidad Católica de Valparaíso, Chile, 1995); para la remisión normativa véanse en especial pp. 69 ss.

${ }^{19}$ Silva Cimma, cit. (n. 4), p. 161.

${ }^{20}$ Cfr. Silva Bascuñan, Alejandro, Tratado de Derecho constitucional (2a edición, Santiago de Chile, Editorial Jurídica de Chile, 2000), V, pp. 125-181

${ }^{21}$ Ley No 19.886: de compras públicas, artículo 22 inciso final: "Un auto acordado, dictado por la Corte Suprema, regulará las materias relativas a su funcionamiento administrativo interno, velando por la eficaz expedición de los asuntos que conozca el Tribunal'. El auto acordado de la Corte Suprema corresponde al Acta 81-2003, del acuerdo celebrado con fecha 20 de octubre de 2003, publicado en el DO. de 30 
tucionales se ha visto afectado por autos acordados, al margen de cualquier señal de alarma. Es así como el año 2004 el Tribunal de Defensa de la Libre Competencia dictó un auto acordado en virtud del cual el ejercicio del derecho de acción, cuando es ejercido con posterioridad a una consulta iniciada de acuerdo al procedimiento regulado por ley, es co nvertido en antecedente en dicho procedimiento de consulta. Dicho de otra manera, este auto acordado otorga a una situación de hecho el efecto de desnaturalizar el ejercicio del derecho de acción en virtud del cual se persigue la protección de derechos ante un tribunal (19 No 3) desligándose, de este modo, del mandato del artículo 76 inciso $2^{\circ}$ (ya que una opinión en un procedimiento de consulta no puede originar el deber de pronunciamiento jurisdiccional asociado al principio de inexcusabilidad). En ese mismo auto acordado se establecen restricciones al ejercicio de la libertad económica, al prohibir la realización de ciertos actos sometidos al procedimiento de consulta, si no es con aprobación del tribunal ${ }^{22}$. El caso del Tribunal de la Libre Competencia es, además, de particular interés para este trabajo, porque la atribución que le otorga la ley para dictar instrucciones de carácter general (Decreto ley No 211, artículo 18 No 3) fue objeto de un requerimiento ante el Tribunal Constitucional por otorgar atribuciones al tribunal para dictar disposiciones reglamentarias sobre materias de libertad económica: pero no por alterar la distribución competencial reglamentaria en perjuicio del Presidente de la República. El tribunal desechó el requerimiento y la naturaleza reglamentaria de estas "instrucciones", sin profundizar sustancialmente en las mismas ${ }^{23}$. En otros casos, como por ejemplo el artículo 100 del Código Orgánico de Tribunales, la ley entrega a los autos acordados la regulación de medidas cuyo grado de afectación de los derechos fundamentales hace discutible que puedan radicarse en un nivel normativo distinto del de la propia ley. Más recientemente, vía autos acordados o actas de distinta naturaleza, la Corte Suprema ha intervenido en materias de organización administrativa de los tribunales - por ejemplo, reestructurando el trabajo de las unidades administrativas que la ley regula al interior de los tribunales de familia-.

La sustancia de los autos acordados es de claro carácter reglamentario ${ }^{24}$.

de diciembre de 2003. Este auto acordado contiene disposiciones que parcialmente cubren materias reguladas en el COT. y otras disposiciones legales.

${ }^{22}$ Auto acordado del Tribunal de la Libre Competencia de 22 de julio del 2004, acuerdo $3^{\circ}$.

${ }^{23}$ Sobre este punto, véase: Grunberg Pilowsky, Jorge, La potestad reglamentaria del Tribunal de Defensa de la Competencia: un tema conflictivo en la reforma al DL. 211, en Revista de Derecho Público 66 (2004), pp. 225-250.

${ }^{24}$ Así, ya a principios de la década de 1970, Weinstein, Graciela, La naturaleza 
Se trata de disposiciones generales y abstractas que emanan del ejercicio de potestades administrativas. La circunstancia de que el órgano del cual emanan sea aquél a quien se le encomienda de manera principal el ejercicio de la función jurisdiccional no altera el hecho de que no ejerce esta función jurisdiccional cuando dicta un auto acordado. De aquí la necesaria distinción: el auto acordado no es dictado por una autoridad administrativa, pero sí en ejercicio de una potestad administrativa.

La evolución en esta materia, anterior a la reforma constitucional del año 2005, difiere en sus supuestos de aquellos que presenta el actual texto constitucional. Mientras que el único sustento positivo de las facultades de la Corte Suprema, hasta antes de dicha reforma, era el artículo 79 (hoy artículo 82) de la Carta, que consagraba la superintendencia directiva, correccional y económica de la Corte Suprema, la reforma del 2005 incluye una referencia expresa a los autos acordados emanados de la propia Corte, de las cortes de apelaciones y del Tribunal Calificador de Elecciones (artículo 93 inciso $1^{\circ}$ № 2). Esta diferencia pone de manifiesto un error usualmente cometido en este ámbito. Es así como se sostenía que la superintendencia económica de la Corte Suprema contenía, por sí misma y sin necesidad de habilitación legal, la atribución para dictar autos acordados de carácter reglamentario, afirmación que provenía de la identificación de la facultad de superintendencia económica de la Corte Suprema, con las facultades económicas de los tribunales. Así, Hugo Pereira Anabalón, quien reconoce que la facultad de dictar autos acordados se funda en las facultades económicas de los tribunales y luego, a párrafo seguido, expresa que "Tales potestades se entregan en forma especial a la Corte Suprema en los artículos 82 de la Constitución Política y 96 No 4,99 i. $1^{\circ}$ y $3^{\circ}$ del Código Orgánico de Tribunales; a las Cortes de Apelaciones en el artículo 66 inciso $4^{\circ}$ de este código, y a los tribunales especiales según se desprende del artículo $5^{\circ}$ inciso $4^{\circ}$ de ese texto" ${ }^{25}$. Francisco Zúñiga Urbina, en un trabajo anterior a la reforma del año 2005, ve en la atribución de potestades de superintendencia a la Corte Suprema el otorgamiento de poderes explícitos de una potestad normativa ${ }^{26}$.

El problema que plantea este enfoque es que el contenido de las facultades de control o supervisión no es, de una manera lógicamente

jurídica del auto acordado, en Revista de Derecho Procesal 1 (Santiago, 1971), pp. 5-34. La autora funda la potestad para dictar estos preceptos en la autonomía funcional que nace de la calidad de poder público que tiene el Poder Judicial.

${ }^{25}$ Pereira Anabalón, Hugo, Los autos acordados, en Gaceta Jurídica 327 (Santiago, septiembre de 2007), p. 23.

${ }^{26}$ Zúníiga Urbina, Francisco, Corte Suprema y sus competencias. Notas acerca de su potestad normativa (autos acordados), en Ius et Praxis 4 (1998) 1, p. 228. 
necesaria, igual a las facultades que se trata de controlar, de modo tal que no era ni es correcto, a nivel constitucional, construir las potestades de superintendencia económica de la Corte Suprema sobre la base de las facultades económicas atribuidas a los tribunales. La desviación conceptual se explica en parte porque, en lo tocante a la estructura y atribuciones de la judicatura en Chile, nuestro sistema de fuentes no se encuentra plenamente racionalizado, e incorpora un fuerte componente tradicional, como lo demuestra el fallo de Tribunal Constitucional recaído en el rol oo 783, que se trata en los puntos siguientes ${ }^{27}$. Si se prescinde de este componente tradicional y se atiende estrictamente a la Constitución vigente, puede sostenerse que el contenido de la superintendencia que la Constitución atribuye a la Corte Suprema está completamente entregado a la ley, consistiendo el mandato constitucional exclusivamente en la regla de que, cualquiera fuese el contenido de dicha superintendencia, debía corresponderle a la Corte Suprema ${ }^{28}$.

El punto, por lo demás, no es meramente teórico. Es así como la propia Corte Suprema trató en alguna oportunidad de justificar un contenido intrínseco (o sea, de directa fuente constitucional, y no legal) de su superintendencia disciplinaria, frente a una ley que limitaba sus facultades invalidatorias de resoluciones judiciales en el caso del recurso de queja ${ }^{29}$.

${ }^{27}$ Otro ejemplo de este componente tradicional se encuentra en la aceptación de que órganos jurisdiccionales cuya integración se encuentra constitucionalmente fijada, incorporen una integración extraordinaria de rango legal. Es así como una disposición legal que instituyese la figura de diputados suplentes sería sin lugar a dudas declarada inconstitucional: no obstante, tanto la Corte Suprema como el Tribunal Constitucional, regulados por disposiciones constitucionales que establecen de manera precisa el número de sus miembros, sus requisitos y políticamente complejas modalidades de nombramiento, cuentan con abogados integrantes o ministro suplentes, en su caso, regulados a nivel legal.

${ }^{28}$ La justificación de este aserto queda clara si se contrasta el ordenamiento constitucional vigente en 1833 (artículo 113) con la Carta de 1925. Ésta recoge a nivel constitucional el encargo que la Carta de 1833 hacía a la ley, esto es, definir el órgano al cual le correspondía la superintendencia sobre tribunales. La eliminación, en la Carta de 1980, de la referencia a la ley que contenía el artículo 86 de la Constitución de 1925 no puede entenderse en el sentido de haber constitucionalizado todas las atribuciones a la sazón vigentes, reguladas por ley: máxime ante la presencia del cometido al legislador orgánico para que hiciese esa regulación, y la correspondiente referencia en la disposición transitoria, sobre la calificación de las disposiciones legales vigente a la fecha de entrada en vigor de la Constitución. En una tesis contraria entiendo la posición de Francisco Zúñiga, en la obra citada, pp. 225, 331.

${ }^{29}$ El año 1996 la Corte Suprema reclamó para sí, como directamente emanada de su facultad de superintendencia disciplinaria, la de decidir si imponer o no sanciones disciplinarias en el caso de invalidarse una resolución vía recurso de queja: 
A partir de esto se reformó la Constitución en un sentido que refuerza lo sostenido aquí. En efecto, se agregó al entonces artículo 79 (hoy 82) de la Constitución un precepto que comienza: "Los tribunales superiores de justicia, en uso de sus facultades disciplinarias [...]", permitiendo así el contraste, en una interpretación sistemática de la Carta entre "superintendencia disciplinaria" de la Corte Suprema y "facultades disciplinarias" de los tribunales, idea que se puede hacer extensiva a las demás facultades y sus respectivas superintendencias.

\section{FACULTADES NORMATIVAS DE LOS TRIBUNALES: \\ LA REFORMA CONSTITUCIONAL DEL AÑO 2005 Y EL FALLO DEL TRIBUNAL CONSTITUCIONAL EN LA CAUSA ROL No 783}

Así las cosas, la reforma del año 2005 introduce la referencia a los autos acordados de la Corte Suprema, las cortes de apelaciones y el Tribunal Calificador de Elecciones. El panorama, entonces, cambia, ya que la propia Constitución valida la producción normativa de los autos acordados a nivel de estos tribunales. El Tribunal Constitucional toma nota de este matiz en su sentencia recaída en rol No 783 cuando señala que "Si el artículo 93 No 2 [sic] de la Carta Fundamental otorga a esta Magistratura competencia para revisar la constitucionalidad de estas normas, es evidente que valida esta competencia" (considerando 24\%). Sin embargo, al analizar la fuente de la facultad para dictar autos acordados, el Tribunal Constitucional elige un camino de dudosa constitucionalidad, dejando al descubierto el componente de legitimación tradicional al que se ha aludido precedentemente. En efecto, señala el Tribunal que "desde siempre" se ha entendido que la capacidad para dictar autos acordados proviene de las facultades económicas que competen, en primer lugar, a la Corte Suprema, aunque también a las cortes de apelaciones. Este es un cuestionable giro de nuestro Tribunal Constitucional hacia fuentes no jurídicas, o al menos no jurídico-positivas del ordenamiento jurídico público de nuestro país. ¿Es la referencia a una práctica inmemorial fuente de Derecho público en Chile? Si alguna duda

de este modo, una ley que limitara dicha facultad sería inconstitucional (rol No 11951, 26 de junio de 1996, en Gaceta Jurídica 192 (1996), pp. 102-105). A fin de poner coto a esto, se promulga una reforma constitucional con la Ley No 19.541, de 22 de diciembre de 1997, que agrega al entonces artículo 79, hoy artículo 82, el siguiente precepto: "Los tribunales superiores de justicia, en uso de sus facultades disciplinarias, sólo podrán invalidar resoluciones jurisdiccionales en los casos y forma que establezca la ley orgánica constitucional respectiva" Esta reforma, si se observa bien, era innecesaria a la luz del artículo $7^{\circ}$ inciso $2^{\circ}$ de la Constitución, y por tanto, debe entenderse como respuesta a un déficit en la debida comprensión constitucional de dicha disposición. 
queda respecto de la respuesta que el Tribunal Constitucional da a esta pregunta, basta con leer el cierre del mismo considerando 240: "El reducido ámbito regulatorio que la requirente pretende asignarle a los autos acordados no se aviene con la tradición de las importantes cuestiones que, desde la época de la Colonia, la Real Audiencia primero y luego la Corte Suprema vienen regulando por medio de autos acordados". Aquí se afirma de manera expresa una reserva de regulación, en materias relevantes, y fundada en la tradición, en favor de los autos acordados.

En realidad, estas referencias eran absolutamente prescindibles en la sentencia, por lo que llaman aún más la atención sobre la pervivencia de los criterios tradicionales en la concepción de nuestra judicatura, y sobre la inconveniencia de incorporarlos en un fallo "de acuerdo a Derecho" (artículo 92 inciso penúltimo), en un sistema jurídico que pretende tener un carácter racional normativo basado, al menos en el ordenamiento jurídico público, en el derecho positivo. Si no mantenemos nuestro apego a esta premisa, el sentido atribuido al inciso $2^{\circ}$ del artículo $7^{\circ}$ de la Constitución empieza a diluirse peligrosamente. Por ejemplo: la fuente de la facultad de las cortes de apelaciones para dictar autos acordados se encuentra en el artículo 93 de la Carta, y no en otros preceptos, ni en la tradición. Esto debe resaltarse al leer, en la sentencia en comento, que el Tribunal señala que la facultad para dictar autos acordados tiene consagración constitucional expresa en el artículo 82: "[...] se ha entendido que la capacidad para dictar autos acordados proviene de las llamadas facultades económicas que competen, en primer lugar, a la Corte Suprema, aunque también a las Cortes de Apelaciones. Esta facultad tiene igualmente consagración constitucional expresa en el artículo 82, precepto que viene repitiéndose en nuestras cartas fundamentales desde 1828" (considerando $24^{\circ}$ ). Cabe preguntarse de dónde, dentro del artículo 82, el Tribunal desprende la facultad de las cortes de apelaciones para dictar autos acordados. Lo que este artículo consagra son las facultades disciplinarias de los tribunales superiores, y la superintendencia directiva, correccional y económica de la Corte Suprema sobre todos los tribunales de la Nación: pero no otorga a facultades económicas a las cortes de apelaciones: las que tengan (en virtud de la ley, y tras la reforma del 2005, la de dictar autos acordados en virtud del artículo 93 de la Constitución) quedan sometidas a la superintendencia de la Corte Suprema, pero el artículo no dice nada más. Y si el Tribunal quiere ver algo más en el artículo 82, se reitera la pregunta ¿cómo entiende el Tribunal el alcance de la exigencia de consagración expresa de autoridad o derechos prevista en el artículo 7 inciso $2^{\circ}$ ? 
VI. ÁMBITO DE LA POTESTAD REGLAMENTARIA EJERCIDA

A TRAVÉS DE AUTOS ACORDADOS Y EL FALLO DEL TRIBUNAL CONSTITUCIONAL EN LA CAUSA ROL No 783

Tanto antes de la reforma del 2005, como después de su entrada en vigencia, se plantea la cuestión relativa a los contenidos que un auto acordado puede abordar con su regulación. Al respecto, Francisco Zúñiga escribe: "[...] los autos acordados dictados por la Corte Suprema [...] no pueden insertarse en el ordenamiento jurídico como fuente formal a partir del principio de competencia, ya que la citada potestad no tiene contenidos normativos predeterminados por la Constitución. Esto significa que los autos acordados (jurídicos y administrativos), es decir, referidos a la ley procesal o al servicio judicial, deben subordinarse a la ley, y al sistema de reparto de potestades normativas diseñadas en la Constitución" ${ }^{30}$. El problema que planteaba esta postura, antes de la reforma del año 2005, es que, si los autos acordados debían arreglarse al sistema de reparto de potestades normativas diseñadas en la Constitución, quedaban fuera: lo que no corresponde regular a la ley, es materia de potestad reglamentaria, salvo las habilitaciones de potestades normativas expresas, dentro de las cuales no se encontraban, a la sazón, los autos acordados. Tras la reforma del año 2005, la facultad para dictarlos no puede ser discutida, pero se mantiene la pregunta sobre su ámbito regulatorio que, siguiendo la situación de los demás órganos constitucionales con habilitación constitucional normativa distinta a la autoregulatoria o interna ${ }^{31}$, debería ser definido por ley.

Esta cuestión también es abordada por el fallo del Tribunal Constitucional en la causa rol No 783. Hecha la referencia al fundamento tradicional de la facultad para dictar autos acordados, el Tribunal pasa a examinar la que parece ser la cuestión de fondo: ¿cuál es el alcance de esta facultad de dictar autos acordados? El Tribunal intenta una línea argumental basada en la independencia del Poder Judicial (considerando 25\%). Es cierto que ella podía servir para limitar el ejercicio de la potestad reglamentaria presidencial, en materias no entregadas a la ley, y que pudiesen reclamarse para el ámbito de los autos acordados, en especial dentro de aquella faceta de la independencia que es la autonomía regulatoria. Pero esta línea argumental se encuentra con dos obstáculos. El primero es que la Constitución en ninguna parte consagra de manera explícita la independencia del Poder Judicial. Y por otro lado, la Constitución no prevé una reserva general o especial de regulación a favor de la judicatura, como sí la contempla en el caso de los órganos citados anteriormente, sub II. Aquí se

\footnotetext{
${ }^{30}$ ZúNIIGA, cit. (n. 24), p. 231.

${ }^{31}$ Véase la nota 6.
} 
limita a mencionar el instrumento o acto regulatorio. Cuando se examina la Constitución de manera sistemática se llega a la conclusión de que allí donde la Carta ha querido justificar una excepción al carácter residual del reglamento autónomo respecto de la ley dentro del sistema de fuentes, lo ha hecho otorgando las habilitaciones normativas a los respectivos órganos. ¿Debe entenderse la mera mención de los autos acordados, como objeto de control de constitucionalidad, al modo de una habilitación constitucional genérica de la respectiva potestad normadora? Pero si es así, queda abierta de todos modos la pregunta: ¿con qué contenido? Esta pregunta no es trivial, ya que no sólo viene a definir el ámbito normativo de los autos acordados respecto de la potestad reglamentaria del Presidente de la República, sino que respecto del propio legislador que pudiese entrar a regular la competencia para dictar estos autos acordados.

La solución que da el Tribunal parece inaugurar un nuevo principio o criterio para tratar el sistema de fuentes en la Constitución, y la forma en que éstas operan, ya que utiliza como criterio de habilitación el de subsidiariedad: existirían materias que no se encuentran asignadas estrictamente al ámbito legal, sino que en razón de un criterio de prevención, de tal modo que, mientras no han sido reguladas por el legislador, cabría a los tribunales ordenarlas mediante un auto acordado. Si bien el fallo señala en su considerando $25^{\circ}$ que los autos acordados no pueden regular materias que el constituyente ha reservado al legislador, en el mismo considerando $25^{\circ}$, la sentencia reza como sigue: "En aspectos de funcionamiento en que el legislador no ha establecido normas o que expresamente la Constitución no la ha reservado a éste, el propio órgano judicial puede auto regularse". Un análisis por ítems expone el contenido de esta afirmación del Tribunal:

i) si se trata de aspectos en que el legislador no ha establecido normas $^{32}$ porque no son de su competencia, la afirmación carece de toda sustancia;

ii) si se trata de aspectos en que el legislador no ha establecido normas, y corresponde a su ámbito competencia, el Tribunal propone que la inacción del legislador otorga competencias a los tribunales para regular la materia;

iii) si se trata de materias que la Constitución no ha entregado expresamente al legislador, que de acuerdo al mandato del artículo 32 No 6

\footnotetext{
${ }^{32}$ Mantengo aquí el uso de la terminología del propio Tribunal. En el concepto del autor de estas líneas el legislativo -y cualquier otra potestad reguladora- no establece "normas" sino que preceptos, o textos normativos. La norma, en esta concepción, sería sólo una categoría intelectual, resultante de un proceso de interpretación o construcción normativa, cuya paráfrasis puede coincidir con el enunciado normativo del texto, pero no se confunde con éste.
} 
corresponden a la potestad reglamentaria del Presidente de la República, el tribunal no justifica cómo delimita esa competencia respecto de la correspondiente potestad normativa de los tribunales.

Es el segundo caso el que llama más la atención, ya que el Tribunal Constitucional no llega a explicar cuál sería el fundamento constitucional de esta atribución de competencias normativas supletorias que habilita a las cortes de apelaciones y a la Corte Suprema para regular una materia de ley (ya que por algo se habla de un ámbito en que el legislador no ha dictado la pertinente regulación) por el hecho de que el legislador no haya ejercido sus competencias.

\section{COLOFÓN: LAS FACULTADES NORMATIVAS DEL MINISTERIO PÚBLICO}

Todo el panorama reseñado se hace un poco más complejo al considerar la técnica legislativa empleada por el constituyente derivado en la reforma que introdujo la figura del ministerio público en 1997, y por el legislador orgánico respectivo. A pesar de tratarse claramente de un órgano de naturaleza administrativa, y jerarquizado, no se le otorga a nivel constitucional una potestad reglamentaria, sino que se recurre al préstamo terminológico del híbrido jurisdiccional-administrativo, consagrando en su beneficio una superintendencia. Es así como la Constitución señala, en su actual artículo 91 (ex. 80 inciso 10): "El Fiscal Nacional tendrá la superintendencia directiva, correccional y económica del Ministerio Público, en conformidad a la ley orgánica constitucional respectiva". De acuerdo a la sentencia recién comentada del Tribunal Constitucional, habría que asumir que, al menos en lo económico, esta facultad implica, para el fiscal nacional, la facultad de dictar autos acordados o actos análogos. Claramente, la ley orgánica no lo entiende así y da a esta potestad el nombre que debió haber tenido en términos de una rigurosa técnica constituyente. Denomina "reglamentos" a los actos que produce el fiscal nacional en virtud del ejercicio de la superintendencia directiva, correccional y económica que le confiere la Constitución (artículo 17 letra d), Ley No 19.640: Orgánica constitucional del Ministerio Público). Sin embargo, la ley incurre aquí en una leve imprecisión: los tres ámbitos de la superintendencia vendrían a ejercerse, de acuerdo a la ley orgánica, vía reglamentos del fiscal nacional. De esto se derivan dos consecuencias: La primera, los reglamentos no sólo serían expresión de la superintendencia económica del fiscal nacional, sino que también de su superintendencia directiva y correccional; la segunda, al parecer quedarían excluidos, del ámbito de la superintendencia, los actos concretos de ejercicio de la misma. Lo que en todo caso es indiscutible en este cuerpo normativo, es la calificación como "reglamentos" de los actos 
normativos de carácter general que emanan del fiscal nacional en ejercicio de su superintendencia.

El problema competencial planteado con respecto a los autos acordados se repite aquí, aun cuando con alguna variante. En efecto, en dicho precepto la ley habla de la emisión de "los reglamentos que correspondan" en virtud de dicha superintendencia, y sólo agrega una precisión para acotar esta referencia, cuando señala: "En ejercicio de esta facultad determinará la forma de funcionamiento de las fiscalías y demás unidades del ministerio público, $y$ el ejercicio de la potestad disciplinaria correspondiente". Queda planteada entonces, la pregunta relativa al ámbito de competencias normativas que, en lo restante, cabe reconocer al fiscal nacional en ejercicio de su potestad reglamentaria.

Cuestión aparte la constituye la potestad reglamentaria que, bajo la denominación de "instrucciones generales" le otorga la citada ley orgánica en la letra a) del artículo 17. A pesar de su nombre, a estas instrucciones cabría calificarlas dentro de lo que suele llamarse la "potestad reglamentaria externa" en cuanto su cumplimiento afectará a terceros ajenos a la administración: imputados, víctimas y testigos, como destinatarios de las correspondientes acciones de investigación, acusación y protección ${ }^{33}$. La cuestión que se plantea aquí es la de la fuente constitucional de esta potestad. Las posibilidades son acotadas. Una de ellas sería incluir esta potestad dentro de la atribución constitucional de superintendencia, entendiendo la redacción del artículo 17 letra d) de la Ley No 19.640 simplemente como un error en cuanto parece agotar en los referidos reglamentos la atribución de superintendencia del Fiscal Nacional. Otra sería querer radicarla exclusivamente en el carácter de jerarca que tiene el fiscal nacional, en virtud del artículo 83, de modo tal de entender la jerarquía administrativa como constitucionalmente vinculada a potestades reglamentarias - argumento que, sin embargo, se rechaza generalmente en la construcción de una potestad reglamentaria del Presidente de la República a partir del artículo 24 . Una tercera alternativa sería entender estas instrucciones generales como la opción legislativa de determinar el grado de independencia, autonomía y responsabilidad que tendrán los fiscales en la dirección de la investigación y en el ejercicio de la acción penal pública,

${ }^{33}$ Dada aquí la misma razón -actos normativos resultantes del ejercicio de la superintendencia directiva, correccional y económica- no logra entenderse la omisión, en la reforma del año 2005 a las atribuciones del Tribunal Constitucional, el por qué no se incorporaron los reglamentos a que alude el artículo 17 letra d) al control de constitucionalidad en virtud del artículo 93 inciso $2^{\circ}$ No 2 . Sin embargo, más importante aún para potenciales afectados por actos normativos del ministerio público resulta el control de estas instrucciones generales de la letra a). 
que la Constitución encomienda a la ley orgánica en el actual artículo 84 inciso $2^{\circ}$, en cuyo caso sólo queda fuera de la cobertura constitucional la atribución legal orgánica relativa a las instrucciones generales en cuanto pueda referirse a la protección de testigos.

\section{CONCLUSIÓN}

Cuando se realiza un examen de la distribución de competencias reglamentarias a nivel constitucional, y se contrasta con la misma a nivel legislativo, o la que resulta de la jurisprudencia, u ocasionalmente de la mera práxis institucional de los órganos de control, se aprecia una discordancia importante. El diseño constitucional es bastante claro; existe una potestad normativa entregada al ámbito de la ley, y una potestad normativa entregada al Presidente de la República con carácter residual, salvas las excepciones en que la propia Constitución contempla potestades normativas específicas. El desarrollo legislativo ha modificado esta distribución entregando facultades reglamentarias a una serie de órganos que no se encuentran sometidos a la potestad de instrucción del Presidente de la República y respecto de los cuales, entonces, no puede predicarse que se trate de una regulación de la potestad reglamentaria del Presidente. Por otro lado, ni las potestades normativas de los tribunales superiores -en especial de la Corte Suprema- ni las del fiscal nacional reciben un tratamiento que permita su inserción en un modelo que permita explicar con claridad, y de un modo compatible con la Constitución, la distribución de potestades. Si nuestra doctrina y nuestra jurisprudencia vienen desde hace tiempo predicando como principio básico de nuestro sistema constitucional el de la vigencia normativa directa de la Carta Fundamental, es entonces hora de hacerse cargo de este déficit de fuerza normativa de la Constitución y lograr que la distribución de competencias normativas que contempla se plasme en el desarrollo institucional.

[Recibido el 6 y aceptado el 10 de noviembre de 2009].

\section{BIBLIOGRAFÍA}

Aldunate Lizana, Eduardo, La evolución de la función de control de la Contraloría General de la República, en Revista de Derecho de la Pontificia Universidad Católica de Valparaíso 26 (2005), pp. 19-29.

Cordero Quizacara, Eduardo, La potestad reglamentaria en el Derecho público chileno (Memoria de prueba para optar al grado de licenciado en ciencias jurídicas y sociales, Facultad de Ciencias Jurídicas y Sociales de la Universidad Católica de Valparaíso, Chile, 1995). 
Grunberg Pilowsky, Jorge, La potestad reglamentaria del Tribunal de Defensa de la Competencia: un tema conflictivo en la reforma al DL. 211, en Revista de Derecho Público 66 (2004), pp. 225-250.

Pereira Anabalón, Hugo, Los autos acordados, en Gaceta Jurídica 327 (septiembre de 2007).

Silva Bascuñán, Alejandro, Tratado de Derecho constitucional (2a edición, Santiago de Chile, Editorial Jurídica de Chile, 2000), V.

Silva Cimma, Enrique, Derecho administrativo chileno y comparado. Introducción y fuentes (4a edición, Santiago de Chile, Editorial Jurídica de Chile, 1996).

Weinstein, Graciela, La naturaleza jurídica del auto acordado, en Revista de Derecho Procesal 1 (Santiago, 1971).

ZúÑIga Urbina, Francisco, Corte Suprema y sus competencias. Notas acerca de su potestad normativa (autos acordados), en Ius et Praxis 4 (1998) 1. 